\title{
Perception on the abortion laws in Sri Lanka: A community based study in the city of Colombo
}

\author{
M S Suranga ${ }^{1}$, K T Silva ${ }^{2}$, L Senanayake ${ }^{1}$ \\ (Index words: abortion, Sri Lanka, fetal abnormalities, miscarriage)
}

\begin{abstract}
Introduction Abortion is legally permitted in Sri Lanka, only if it is performed to save the mother's life. However, it is estimated that a large number of induced abortions take place in Sri Lanka. Knowledge and attitudes towards induced abortion in the society are key issues influencing the policy response towards changes in the law. This study aimed to assess the knowledge and attitudes of adults towards induced abortion in Sri Lanka.
\end{abstract}

Methods Six Grama Niladhari Divisions (GNDs) and five to eight housing clusters from each GND were selected from Thimbirigasyaya Divisional Secretariat Division using multi stage stratified random sampling. Fifty households were systematically selected from each GND. An interview was scheduled among 743 residents aged between 19 to 49 years of age after receiving written informed consent.

Results Only $11 \%$ of the respondents knew the situations in which abortion was legal in Sri Lanka. Approximately one tenth of the respondents $(11 \%)$ did not agree with the current law which allows an induced abortion only to save the life of the mother. However, a majority agreed to legalization of abortion for rape (65\%), incest (55\%) and pregnancies with lethal fetal abnormalities (53\%). Less than one tenth of respondents agreed with legalisation of induced abortion for other reasons such as con-traceptive failure $(6 \%)$, poor economic conditions $(7 \%)$ and, on request $(4 \%)$.

Conclusions Although the society rejects abortion on request majority are in favour of allowing abortions for rape, incest and fetuses with lethal abnormalities.

Ceylon Medical Journal 2016; 61: 171-175

http://doi.org/10.4038/cmj.v61i4.8384

\section{Introduction}

Abortion is permitted in Sri Lanka only if it is performed to save the mother's life [1,2]. Even with a high national contraceptive prevalence rate of $68 \%$ where $50 \%$ use modern methods, women have unwanted pregnancies and some of them resort to abortion outside the law [3]. As Sri Lanka has a very restrictive law on abortion and a strict law enforcement mechanism, women avoid giving information regarding undergoing abortions and it is difficult to determine the prevalence rate for illegal abortions. A study undertaken in 1990s estimated that 125,000 to 175,000 abortions, mostly illegal, are performed a year [4]. Another study conducted in 2000 estimated a much higher rate of 658 induced abortions per day amounting to 240,170 per year, giving an abortion ratio of 741 per 1000 live births [5]. A later study applying Bongarts' model showed an increased rate of induced abortions from 0.035 per woman in 1993 to 0.087 per woman in 2007 [6].

The significance of illegal abortion in the health context is evident from the fact that it contributes to $12.5 \%$ of all maternal deaths and it is the third most common cause of maternal death [7]. Table 1 illustrates the historical trends in maternal mortality and the contribution by septic abortion.

Table 1. Cause specific maternal mortality rate for abortion in Sri Lanka

(Family Health Bureau Annual Reports 2005-2013)

\begin{tabular}{cc}
\hline Year & $\begin{array}{c}\text { Cause specific maternal mortality } \\
\text { rate for abortion / 100,000 }\end{array}$ \\
\hline 2005 & 4.2 \\
2006 & 4.8 \\
2007 & 3.8 \\
2008 & 4.2 \\
2009 & 5.2 \\
2010 & 4.5 \\
2011 & 3.0 \\
2012 & 3.7 \\
2013 & 0.8 \\
2014 & 3.98 \\
\hline
\end{tabular}

${ }^{1}$ Family Planning Association and ${ }^{2}$ University of Peradeniya, Sri Lanka.

Correspondence: MSS, e-mail: <suranga@fpasrilanka.org>. Received 6 June 2016 and revised version accepted 29 August 2016.

This is an open-access article distributed under the terms of the Creative Commons Attribution License, which permits unrestricted use, distribution, and reproduction in any medium, provided the original author and source are credited. 
According to the Penal Code of Sri Lanka, any person performing an illegal abortion is liable to be punished with imprisonment up to three years [8]. According to section 304, in case of death of such a woman, the person performing an illegal abortion shall be punished with imprisonment up to 20 years [9].

Opinions of Sri Lankans became evident during attempts made in 1970s' and 1990s' to change the law to include rape, incest and fetal abnormalities as indications for legal abortion through a private member's bill and a cabinet paper respectively. Both were unsuccessful due to pressure from groups such as religious leaders.

Perception of the Sri Lankan adult population towards induced abortion can influence the decision on the fate of unwanted pregnancies by individuals and couples, as well as the health sector policy response towards providing safe abortion services. This study attempted to assess knowledge of adults of the existing law and opinion about future changes in the law.

\section{Methods}

The study sample included all adults, aged 19 to 49 who lived in Colombo city for at least one year. Using systematic Probability Proportionate to the Size (PPS) cluster selection method six Grama Niladhari Divisions (GND) were selected from the Thimbirigasyaya Divisional Secretariat Division (DSD). The selected GNDs were divided into housing clusters using data derived from the 2012 Department of Elections Registry. Five to eight housing clusters were selected from each GND using PPS cluster selection method. Fifty households were identified from each GND. Starting from a random point, every third household was selected for the survey until the expected sample size was attained. The primary sample size for the household survey was 300 households using a standard sample size calculation formula for household surveys [11]. A structured questionnaire was administered after obtaining written informed consent from all the participants by a team of trained graduates who had specialised in sociology from University of Colombo. The questionnaire consisted of two components; a common questionnaire for households and the master questionnaire for individual respondents. The questionnaire was initially developed after a consultative process in English and translated into local languages (Sinhala and Tamil) by two professional translators. The questionnaire was pre tested using fifteen respondents representing both genders and all age groups to determine the accuracy of translation and whether the respondents were able to understand and respond to the questions, terms, and words of the questionnaire. Field data collectors were trained on administering the questionnaire, ethical considerations and maintaining privacy and confi-dentiality. Interviews were conducted individually in an environment which ensured privacy (one on one) without involvement of or within the hearing of a third person. Approval for the study was obtained from the Ethics Review Committee of Sri Lanka Medical Association. Field data collection was conducted from February to April 2014. The data was statistically analysed using SPSS software.

\section{Results}

Data were collected from 271 of 300 selected households. The remaining 29 households had no person eligible to participate in the study or they were not willing to participate in the study. Of the 1022 eligible individuals resident in the 271 households only 825 $(80.7 \%)$ were available for the interview on the day of the visit. From these a total of 743 valid completed questionnaires $(90.06 \%)$ were collected. The average age of the respondents was 33 years $(\mathrm{SD}=11.15)$ and consisted of $305(41.2 \%)$ males and $435(58.8 \%)$ females. Table 2 describes the socio-demographic characteristics of the sample.

Table 2. Socio-demographic profile of the respondents including a comparison with national, district and divisional secretariat divisional censes

\begin{tabular}{|c|c|c|c|c|c|}
\hline \multicolumn{2}{|c|}{ Characteristic } & Sample Number & Thimbirigasyaya & Colombo & Sri Lanka** \\
\hline & Category & Number of respondents & $\%$ & $\%$ & $\%$ \\
\hline \multirow[t]{3}{*}{ Sex } & Female & $435(58.78)$ & 49.85 & 50.78 & 51.49 \\
\hline & Male & $305(41.22)$ & 50.14 & 49.21 & 48.51 \\
\hline & Total & $740(100.00)$ & & & \\
\hline \multirow{6}{*}{$\begin{array}{l}\text { Age } \\
\text { in years }\end{array}$} & $19-24$ & $255(34.32)$ & & & \\
\hline & $25-30$ & $118(15.88)$ & & & \\
\hline & $31-36$ & $53(7.13)$ & & & \\
\hline & $37-42$ & $81(10.90)$ & & & \\
\hline & $43-49$ & $236(31.76)$ & & & \\
\hline & Total & $743(100.00)$ & & & \\
\hline$\overline{\text { Ethnicity }}$ & Sinhalese & $384(51.68)$ & 52.77 & 76.69 & C'snitinue \\
\hline
\end{tabular}




\begin{tabular}{|c|c|c|c|c|c|}
\hline \multirow[t]{2}{*}{ Characteristic } & \multirow[b]{2}{*}{ Category } & \multirow{2}{*}{$\begin{array}{c}\text { Sample Number } \\
\% \\
\text { Number of respondents }\end{array}$} & \multirow{2}{*}{$\begin{array}{c}\text { Thimbirigasyaya } \\
\qquad S D^{* *} \\
\%\end{array}$} & \multirow{2}{*}{$\begin{array}{c}\text { Colombo } \\
\text { District** } \\
\%\end{array}$} & \multirow{2}{*}{$\begin{array}{c}\text { Sri Lanka** } \\
\%\end{array}$} \\
\hline & & & & & \\
\hline & Muslims & $131(17.63)$ & 15.23 & 11.05 & 9.43 \\
\hline & Indian Tamil & $16(2.15)$ & 1.49 & 1.18 & 4.16 \\
\hline & Sri Lankan Tamil & $205(27.59)$ & 28.00 & 10.01 & 11.22 \\
\hline & Burger & $7(0.94)$ & 0.68 & 0.58 & 0.18 \\
\hline & Total & $743(100.00)$ & & & \\
\hline \multirow[t]{6}{*}{ Religion } & Buddhist & $316(42.53)$ & 48.07 & 70.66 & 70.19 \\
\hline & Islam & $136(18.30)$ & 17.49 & 11.76 & 9.71 \\
\hline & Hindu & $165(22.21)$ & 22.31 & 7.89 & 12.61 \\
\hline & Roman Catholic & $50(6.73)$ & 7.63 & 6.80 & 6.10 \\
\hline & Christian - Non RC & $76(10.23)$ & 4.23 & 2.75 & 1.35 \\
\hline & Total & $743(100.00)$ & & & \\
\hline Level of & Less than year 04 & $9(1.23)$ & & & \\
\hline \multirow[t]{6}{*}{ Education } & Year 05-07 & $54(7.36)$ & & & \\
\hline & Year $8-10$ & $146(19.89)$ & & & \\
\hline & $\mathrm{GCE} \mathrm{O} / \mathrm{L}$ and $\mathrm{A} / \mathrm{L}$ & $442(60.22)$ & & & \\
\hline & $\begin{array}{l}\text { Higher education } \\
\text { or Degree }\end{array}$ & $57(7.77)$ & & & \\
\hline & Post graduate & $26(3.54)$ & & & \\
\hline & Total & $734(100.00)$ & & & \\
\hline \multirow[t]{5}{*}{ Marital Status } & Married & $396(53.44)$ & & & \\
\hline & Never Married & $317(42.78)$ & & & \\
\hline & Divorced & $7(0.94)$ & & & \\
\hline & Widow & $21(2.83)$ & & & \\
\hline & Total & $741(100.00)$ & & & \\
\hline
\end{tabular}

\section{Awareness about Sri Lankan law on abortion}

Around one third (37\%) of the respondents answered at least one out of four questions on Sri Lankan law correctly. Only $11 \%$ of the respondents knew the conditions under which abortion was legal. About 12\% were of the view that abortion was legally allowed in Sri Lanka to protect mental or physical health of the mother while $14 \%$ of the respondents were of the view that abortion was legal in Sri Lanka for rape, incest and fetal abnormalities. There were two respondents out of 743 who believed that abortion was legal in Sri Lanka for every situation. Around two thirds of the respondents $(66 \%)$ were of the view that abortion was not allowed under any circumstances. It is interesting to note that within this non-medical community, three fourth of respondents ( $73 \%$ of females and $68 \%$ of males) thought that provision of treatment for a woman who had undergone an illegal abortion was an offence according to the law on abortion. Another important finding was that the female respondents showed significantly higher level of awareness than men.
Table 3. Response to questions related to the existing law

\begin{tabular}{lc}
\hline & $\begin{array}{c}\text { Correct answer } \\
\text { Number (\%) }\end{array}$ \\
\hline $\begin{array}{l}\text { Induced abortion is legal in Sri Lanka under } \\
\text { some circumstances }\end{array}$ & 81 (34\%) \\
In which situations are induced abortion \\
legal in Sri Lanka?
\end{tabular}




\section{Attitudes concerning the abortion law}

It was found that approximately one tenth of the respondents $(11 \%)$ did not agree to termination of the pregnancy even to save the life of the mother which is currently legal. A majority of the respondents agreed that there is a need to legalize abortion for certain conditions such as rape (65\%), incest (55\%) and lethal fetal abnormalities (53\%) (Table 4). However only $30 \%$ of the respondents agreed with the need to legalise abortion when the abnormality was non-lethal.

Less than $10 \%$ of respondents of our study agreed to legalising abortions on account of economic problems $(7 \%)$, contraceptive failure $(6 \%)$, at the request of the couple $(5 \%)$ and at request of the woman (4\%).

Table 4. Response to legalizing abortion

\begin{tabular}{lll}
\hline \multicolumn{1}{c}{ Circumstance } & Number (\%) agreed \\
\hline 01 & $\begin{array}{l}\text { To terminate pregnancy resulting } \\
\text { from rape }\end{array}$ & $483(65 \%)$ \\
02 & $\begin{array}{l}\text { To terminate pregnancy resulting } \\
\text { from rape }\end{array}$ & $406(55 \%)$ \\
03 & $\begin{array}{l}\text { To terminate a pregnancy with lethal } \\
\text { fetal abnormalities }\end{array}$ & $392(53 \%)$ \\
04 & $\begin{array}{l}\text { To terminate a pregnancy with fetal } \\
\text { abnormalities where fetus may survive }\end{array}$ & $222(30 \%)$ \\
05 & $\begin{array}{l}\text { Terminate a pregnancy resulting from a } \\
\text { contraceptive failure }\end{array}$ & $46(6 \%)$ \\
06 & $\begin{array}{l}\text { To terminate a pregnancy on account } \\
\text { of poor economic conditions of the family }\end{array}$ & $50(7 \%)$ \\
07 & $\begin{array}{l}\text { Abortion on the request of the couple } \\
08\end{array}$ & Abortion on the request of the woman \\
\end{tabular}

Interestingly, there is no statistically significant difference in the opinions between males and females regarding legalising abortion for rape, incest and nonlethal fetal abnormalities. Although the numbers who agreed were small, females were more likely to accept legalising abortion for reasons such as economic problems $\left(\chi^{2}=11.582, p<0.001\right)$, contraceptive failures $\left(\chi^{2}=4.12\right.$, $p=0.042)$, at the request of the couple $\left(\chi^{2}=7.703\right.$, $p=0.006)$, and at the request of the woman $\left(\chi^{2}=7.886\right.$, $p=0.005$ ). Younger respondents (age $<25$ years) were more likely to accept legalising abortion for contraceptive failure, poor economic conditions and on the request of the woman or the couple.

\section{Discussion}

Lack of awareness about the current abortion law can influence individual decision making regarding contraceptive use, lead to accessing unsafe abortion and unsafe post abortion care. People have concerns about legal repercussions if they seek post abortion care after an illegal abortion. This misconception may lead to delay in accessing health facilities for treatment of complications after an abortion resulting in high mortality after unsafe abortion. Compared to our findings, a study conducted in 2010 among women with unwanted pregnancies, women with wanted pregnancies and women who had undergone an abortion reported a higher level of awareness [12]. This study concludes that the proportion of those who were aware of the Sri Lankan abortion law among women with unwanted pregnancies $(69.5 \%)$ was lower than the women with wanted pregnancies $(80.4 \%)$ and the women who had undergone an abortion (74.4\%) [12].

Public perception on induced abortion can influence not only the outcome of the unwanted pregnancy but also health sector policy response. Findings of this study highlight that the respondents were more likely to accept abortion in situations where the pregnancy was beyond the control of the woman or when the fetus had no chance of survival; so called "hard reasons". Compared to the findings of our study, a study conducted among Sri Lankan medical students found a higher rate of agreement for hard reasons; fetal abnormalities $(87 \%)$, rape $(78 \%)$ and incest (77\%) [13]. Another study which focused on the attitudes of doctors and medical students also concluded that $87 \%$ of doctors and $80 \%$ of medical students support a change in the law to allow termination of pregnancy for severe congenital abnormality [14].

However, we found that majority were not willing to accept legalising abortion in situations where the pregnancy was within the control of the woman; so called "soft reasons". Similar conservative opinion was noted in another study conducted in 2010 in which over $70 \%$ of women who had undergone abortion did not think that legalising abortion was appropriate or that it was beneficial [12].

In view of public acceptance, government may consider legalising induced abortion for rape, incest and when the fetus has lethal abnormalities. However, liberalising the law on abortion to include cases of rape, incest and fetal abnormality would not significantly reduce the current rate of illegal abortions. This is because, the previous studies have clearly shown, the number of induced abortions following rape, incest and foetal abnormality were small $[10,15]$. Experience in other countries shows that liberal laws alone have not solved the issues of induced abortions [15]. Therefore other related factors must be considered when formulating national policies and legislation.

There were several limitations of our study. This sample drawn from the Colombo City is different from the rest of the country in ethnic, religious and socio-economic characteristics (Table 2). Furthermore only those aged 19-49 were sampled. So, findings cannot be generalised to the rest of the communities, geographical locations or age groups. Only 72.2\% (743 valid responses from 1022 
eligible individuals) valid responses were received due to practical difficulties in contacting respondents and data collection in this highly urbanised setting which may affect the final results.

\section{Conclusions}

Study concludes that awareness of the current law on abortion among Sri Lankan adults living in a selected geographical area was low. A majority of the respondents supported legalisation of abortion for rape, incest and lethal fetal abnormality. Less than one tenth of respondents agreed to legalise induced abortion in other situations such as poor economic conditions, contraceptive failure or on request of the couple or woman.

\section{Acknowledgements}

Authors acknowledge the work done by members of the field survey team CK De Thabrew, I De Silva, Wanigasundara, S Samitha,WMK Wijethunga, S Tissera, T Agus, N Liyanage, D Rajakaruna, K Senadhira, T Moonasinghe, H Wickramasinghe, M Deshapriya, RVP Rajapakshe, T Wickramarathne, C Hettiarachchi, M Samarawickrama, K Yogeshwaran, K Sirinivasan, S Godakanda and NK Weerasinghe.

\section{Conflicts of interest}

There are no conflicts of interest.

\section{References}

1. Sri Lanka Penal Code Section 303. University of Menesota,1883. http://www1.umn.edu/humanrts/research/ srilanka/statutes/Penal_Code.pdf (accessed on Aug 15, 2015).

2. Senanayake L, Willatgamuwa S, Moonasinghe L, Tissera S. Unwanted / Unplanned pregnancies and their aftermath. Colombo: The Family Planning Association of Sri Lanka in collaboration with the College of General Practitioners of Sri Lanka, 2012.

3. Senanayake L. Prevention of unsafe abortion in Asia Ocenia Region. Asia Ocenia Federation of Obstetrics and Gynecology, 2009.
4. De Silva IW. The Practice of Induced Abortion in Sri Lanka. Harword School of Public Health, 1997.

5. Rajapakshe LC. Estimates of Induced Abortion using RRT Technique. Colombo, 2000.

6. Abeykoon AT. Estimates of Abortion Rate in Sri Lanka using Bongaarts Model of Proximate Determinants of Fertility. Colombo: The United Nations Population Fund, 2012.

7. Godakanda S. Regional Workshop on FIGO initiative on unsafe abortion. International Federation of Gynecology and Obstetrics (FIGO). Mumbai, 2016.

8. Panel Code Sri Lanka-Section 303. Panel Code Sri Lanka - Section 303, 1883.

9. Panel Code Sri Lanka-Section 304. Panel Code Sri Lanka - Section 304, 1883.

10. Senanayake L, Willatgamuwa S, Jayasinghe K. Reducing the burden of unsafe abortion in Sri Lanka - A situation analysis and plan of action. Colombo : The Family Planning Association of Sri Lanka, 2008.

11. Department of Economic and Social Affairs, Statistics Division, United Nations Secretariat. Designing Household Survey Samples: Practical Guidelines. United Nations Secretariat, 2005. http://unstats.un.org/unsd/demographic/ sources/surveys/Handbook23June05.pdf. (accessed on Jan $15,2013)$.

12. Thalagala N. Unsafe abortions in Sri Lanka - facts and risk profile. Journal of the Community Physicians of Sri Lanka 2010; 15: 1-12.

13. Wickramasinghe HK, Wickramasinghe IS, Atukorala RK, Weerasurendera B. Attitudes on abortion among a group of Sri Lankan medical students. Colombo: Faculty of Medicine, University of Colombo, 2009.

14. Simpson B, Dissanayake MV, Wickramasinghe D, Jayasekara WR. Prenatal testing and pregnancy termination in Sri Lanka; Views of medical students and doctors. Ceylon Med J 2003; 48: 129-32.

15. Perera J, De Silva T, Gange H. Knowledge, behaviour and attitudes on induced abortion and family planning among Sri Lankan women seeking termination of pregnancy. Ceylon Med J 2004; 49: 114-7. 